\title{
National Student Solar Spectrograph Competition overview
}

Randal Larimer, Angela DesJardins, Joseph Shaw, Charles Kankelborg, Christopher Palmer, et al.

Randal M. Larimer, Angela DesJardins, Joseph A. Shaw, Charles C.

Kankelborg, Christopher Palmer, Larry Springer, Joey Key, W. Berk Knighton, Kevin S. Repasky, Nathan J. Pust, Mitchell K. Hobish, Edmond W. Wilson Jr., Carrie Fitzgerald, Ryan Fitzgerald, Thomas Trickel, Clyde Jensen, Skye Dorsett, Matt Anderson, Jim Boger, Nate McCrady, Jaylene Naylor, Laurie Battle, "National Student Solar Spectrograph Competition overview," Proc. SPIE 8481, Optics Education and Outreach II, $84810 Z$ (15 October 2012); doi: 10.1117/12.965323

Event: SPIE Optical Engineering + Applications, 2012, San Diego, California, United States 


\title{
National Student Solar Spectrograph Competition overview
}

Author(s): Randal M. Larimer, Angela DesJardins, Montana Space Grant Consortium (United States); Joseph A. Shaw, Charles C. Kankelborg, Montana State Univ. (United States); Christopher Palmer, Richardson Gratings ${ }^{\mathrm{TM}}$, a Newport Corp. Brand (United States); Larry Springer, Montana State Univ. (United States); Joey Key, Montana Space Grant Consortium (United States); W. Berk Knighton, Kevin S. Repasky, Nathan J. Pust, Montana State Univ. (United States); Mitchell K. Hobish, Sciential Consulting LLC (United States); Edmond W. Wilson, Jr., Harding Univ. (United States); Carrie Fitzgerald, Ryan Fitzgerald, Montgomery College (United States); Thomas Trickel, Salish Kootenai College (United States); Clyde Jensen, Skye Dorsett, Mount Hood Community College (United States); Matt Anderson, San Diego State Univ. (United States); Jim Boger, Flathead Valley Community College (United States); Nate McCrady, Jaylene Naylor, The Univ. of Montana (United States); Laurie Battle, Montana Tech (United States)

\begin{abstract}
The yearly National Student Solar Spectrograph Competition (NSSSC) is Montana Space Grant Consortium's Education and Public Outreach (EP/O) Program for NASA's Interface Region Imaging Spectrograph (IRIS) mission. The NSSSC is designed to give schools with less aerospace activity such as Minority Serving Institutions and Community Colleges an opportunity for hands on real world research experience. The NSSSC provides students from across the country the opportunity to work as part of an undergraduate interdisciplinary team to design, build and test a ground based solar spectrograph. Over the course of nine months, teams come up with their own science goals and then build an instrument to collect data in support of their goals. Teams then travel to Bozeman, MT to demonstrate their instruments and present their results in a competitive science fair environment. This paper and poster will discuss the 2011-2012 competition along with results as well as provide information on the 2012 -2013 competition opportunities.
\end{abstract}

Keywords: IRIS, NSSSC, Spectrograph, Student Competition, EP/O

\section{INTRODUCTION}

The yearly National Student Solar Spectrograph Competition (NSSSC) is Montana Space Grant Consortium's Education and Public Outreach (EP/O) Program for NASA's Interface Region Imaging Spectrograph (IRIS) mission. "NASA is in a unique position to use scientific space missions like IRIS to foster student interest in science and engineering," said Diane DeTroye, of NASA's education office in Washington, D.C. "Giving students a chance to get hands-on experience often encourages them to pursue and continue STEM studies. This helps build an important pipeline of talent for future NASA missions."

A Spectrograph is an instrument used to measure properties of light over a specific portion of the electromagnetic spectrum by separating the incoming light into its characteristic frequencies of wavelengths (spectrum). Spectrographs have a wide range of complexity from simple grating or prisms to the cutting edge IRIS spectrograph. The goal of this competition is to design and build a spectrograph and carry out a ground-based spectroscopy experiment of the students choosing. Each team has the academic year to declare a science goal, design and build their instrument, collect and analyze data, and perform some type of educational outreach. Teams then travel to Montana to demonstrate their instrument and their findings in a competition-style format.

Optics Education and Outreach II, edited by G. Groot Gregory, Proc. of SPIE Vol. 8481

84810Z · ( 2012 SPIE · CCC code: 0277-786/12/\$18 · doi: 10.1117/12.965323 


\section{COMPETITION OVERVIEW}

\subsection{Project Milestones}

NSSSC details can be found on the competition website: $\underline{\text { http://www.spacegrant.montana.edu/iris/ }}$

The NSSSC has the following project milestones:

1. Declare a science goal: the point is to demonstrate the scientific capability of your spectrograph by "figuring something out".

2. Design and build a spectrograph on a budget of $\$ 2,000$.

3. Use your instrument to collect data, which you will analyze and present at the competition in Montana.

4. Provide educational outreach in your community, such as a demonstration to a class or a presentation on solar science.

5. Present your work during the competition in the form of a research poster and three ten-minute talks (talk topics are: Design \& Build, Outreach, and Results)

\subsection{Technical Rules}

A laptop may be used to interface with your spectrograph for instrument control and data collection. The laptop is not part of the \$2,000 budget and Build Award funds may not be used towards its purchase.

Any type of telescope that is used with your spectrograph, whether it is a single lens or a commercial telescope, must be included in your budget

A selection of diffraction gratings is being provided by Richardson Gratings. Each team is allowed one grating free of charge.

On the competition days, you will have access to a heliostat that provides a fixed beam of sunlight. The maximum diameter aperture that the heliostats can accommodate is four inches; larger apertures are not allowed.

The sun may be your team's object of study. Alternatively, the sun may be used as a light source for an experiment outside of solar science.

\subsection{Build Awards}

Each team can apply for Build Awards in the amount of \$2,000 per team. 


\subsection{Eligibility and Team Composition}

Undergraduate students enrolled in a U.S. college or university are eligible to enter the NSSSC. Unfortunately, due to the funding restrictions imposed by NASA, we are currently unable to accept international teams. Teams must include at least one faculty advisor from a college or university and consist of three to six undergraduate students. A group of universities may work together on a spectrograph entry. Multidisciplinary teams and collaborations between Majority and U.S. Minority Serving Institutions are encouraged. Priority for build awards will be given to Minority Serving Institutions, Community Colleges and institutions with less aerospace activity.

\subsection{Evaluation}

Four Judges will evaluate the Student Solar Spectrograph projects based on four categories: best design, best build, best science observations, and best presentation of results. Judging will be based on the teams' own stated science goals as

well as general performance benchmarks. An example of a general benchmark would be the identification of Fraunhoffer lines in the solar spectrum to demonstrate resolution and sensitivity of your device.

\subsection{Suggested Timeline}

Successfully designing an experiment and building the equipment needed to carry it out may seem like a daunting task, especially in the academic year format of NSSSC. Your team may review this suggested timeline of project milestones, and plan a more detailed timeline according to your team's specific objectives and member availability.

September: Make sure registration is in order. Be underway with research into spectroscopy and possible science goals.

October: Science goal should be clearly stated. Begin designing, choosing optics, etc.

November: Finalize design; calculate theoretical performance capabilities (resolution, intensity, etc.). If design needs are met, begin ordering parts.

December: Test parts as they arrive. Make your own intensive schedule for January-May that includes necessary tasks such as fabrication, testing, troubleshooting, calibration, data collection, data presentation, etc.

February: Have the instrument built and fully operational. Perform in-lab testing.

March: Collect data. Finalize plans for travel/ shipping to Montana.

April: Present data in the context of your own science goal. Consider giving a practice presentation at home, especially for those taking science communication classes or capstone classes.

May: Wrap up your coursework and head to Montana! 


\subsection{Prizes}

Travel awards to a NASA launch for 4 winning teams per year.

Scholarship awards for 4 winning teams per year, 4 students per team at \$3,000/student.

\section{Registered Teams of the 2011-2012 Competition}

In early January 2012, 13 teams registered for the 2011-2012 competition from a variety of Universities and Colleges.

1. Montana State University Team - "Dark Star", Bozeman, MT

2. Harding University - "Harding Solar Spectroscopy Group",Searcy, AR

3. Hobart and William Smith Colleges - "Herons", Geneva, NY

4. $\quad$ Montgomery College - "Montgomery College", Rockville, MD

5. Salish Kootenai College - "SKC", Pablo, MT

6. $\quad$ University of North Dakota - "Surya", Grand Forks, ND

7. Mt. Hood Community College - "Star Catchers", Gresham, OR

8. $\quad$ San Diego State University - "SDSU", San Diego CA

9. $\quad$ Flathead Valley Community College -"FVCC Spectrogeeks", Kalispell, MT

10. Montana State University Team - " $\Gamma \Delta \Sigma \mathrm{J}$ ", Bozeman, MT

11. University of Montana - "GrizSpect", Missoula, MT

12. Montana Tech - "Ad Astra Per Ardua", Butte, MT

13. Montana State University Team - "Rowlands Dark Scintillations", Bozeman, MT

\section{Science Goals for the 2011-2012 Competition}

Selected science goals from the registered teams included the following:

Montana State University "Dark Star" Team - "Our spectrograph has two goals; 1.) Atmospheric Absorption Distinguish absorption features across full spectra 2.) Solar Imaging - Analyze full solar image in wavelength band without a CCD.”

Harding University - "The goal of this research is to measure the atmospheric water vapor in Earth's atmosphere over a period of time to determine what short and long range variations occur." 
Hobart and William Smith Colleges - "Our spectroscope will inform us as to the primary trace gas concentrations in the atmosphere above the device's location and will allow us to make meaningful measurements as to the atmospheric concentrations of ozone, water vapor, and potentially even potent greenhouse gases such as $\mathrm{CO} 2$ and methane ."

Montgomery College - "Our scientific goal is to characterize several light pollution filters and compare our measurements with advertised specifications.”

Salish Kootenai College - "Our team will be researching between 400-700nm on the solar spectrum. Our goal is to get the most accurate readings per nanometer possible with our equipment."

San Diego State University - "Determine the temperature of the sun at different positions along the suns diameter."

Flathead Valley Community College - "Collect data over time to observe the "Sound of Light" by correlating intensity and frequency at a range of wavelengths."

Montana State University "Greek" Team - "To attain a high resolution spectrograph by unconventional and budget efficient means and use to detect the presence of cutting oils on metal for industrial applications."

University of Montana - "There are many different barriers used to block the transmission of harmful solar UV rays to humans, such as sunscreen. We will examine the effect on transmission and absorption of solar UV radiation by various sunlight barriers to determine their relative effectiveness at blocking UVA and UVB; two known ranges of electromagnetic (EM) radiation that have been linked to cancer."

Montana Tech - "Through the use of a ground-based solar spectrograph that uses the infrared solar spectrum as our observing window, we will collect the data and an understanding of selected plants and how they are affected by the infrared spectrum".

Montana State University "Rowlands Dark Scintillations" Team - "Can the eye compete with a sensor? Build two spectrographs and compare them."

\section{Outreach for the 2011-2012 Competition}

Selected outreach events from the registered teams included the following:

Montana State University "Dark Star" Team - "NSSSC promotion at 2011 SPIE Optics and Photonics Conference, spectrograph design presentation at the National Conference for Undergraduate Research, engineering presentations for high school students, spectrograph design presentation at MSU Research Celebration and MSGC Research Symposium, demonstrated spectrograph principles at Astronomy Day, presented Senior Design Project at Montana State University Design Fair." 
Harding University - "Oral Presentations given about NSSSC and the design of our spectrograph to Arkansas Space Grant Consortium Symposium and the Arkansas Undergraduate Research Conference. Future outreach events:

We will prepare an exhibit on the importance of our Sun in the Harding University Library. Handout materials that can be taken by the students will be part of the exhibit and include a handout on interesting facts about the Sun and a handout about the IRIS satellite.

A PowerPoint presentation will be prepared that will tell about: the Sun, the IRIS Satellite, and our participation in the NSSSC. This will be played on the monitors in the two lobbies of the Science and Engineering Building for a period of time this summer and during the fall semester

During summer school, we will place two telescopes on the front lawn that can be used to safely view the Sun. An announcement will be made to the student body to come and visit with the team, look through the telescopes and learn some facts about the Sun

Upon our return to Arkansas, we will submit an article about our visit to the NSSSC with some pictures to be placed in the local newspaper and the area Sunday newspaper, the 3 Rivers Edition, and in each of the students' hometown newspapers."

Montgomery College - "Rockville Science Day is an annual event at Montgomery College since 1999 focused on emphasizing the important of science to youth. There were 60 exhibits ranging from medical sciences to chemistry and astronomy. We were set up outside with our spectrometer aimed at the sun with a laptop hooked up so anyone could take readings. We also included a packet of information outlining the goals and procedures of our project. Just for fun we included a UV bead station where kids could make beads that change color when in UV light. We plan to continue our involvement in Rockville Science Day with future versions of our spectrometer. We also will begin using our spectrometer at public observatory events. Set up a department seminar talk for physics, engineering, and geosciences departments that outlined our project and allowed us to practice or talks.”

San Diego State University - "Public Outreach event called "What Color is the Sun?” presented at San Diego Festival of Science and Engineering featuring a presentation and demonstration that reached over 120 people of all ages."

Flathead Valley Community College - "We gave an interactive presentation given at a rural elementary school to a 4th grade audience with a strong interest in sciences."

Montana State University "Greek" Team - "Participated in Astronomy Day with a table top display and a fold up spectrograph activity for kids. We created three videos to reach more than the Bozeman community and to explain the basic ideas of spectroscopy in an easy-to-understand format by raising awareness for both this competition and the IRIS spectrograph."

http://www.youtube.com/watch?v=tX3zGZ_nHRQ

http://www.youtube.com/watch?v=XraGpE5lREE

http://www.youtube.com/watch?v=bLYKKal0APg 
Montana State University "Rowlands Dark Scintillations" Team - "Met with a group of 8th graders a couple of seniors in a physics class in the small town of Manhattan, MT. Explained the science behind spectroscopy, informed the young students of the opportunities of going into a science field, demonstrated the spectrograph we had built and explained the practical applications."

\section{Spectrograph Design and Build for the 2011-2012 Competition}

Selected design and build pictures from the registered teams included the following:

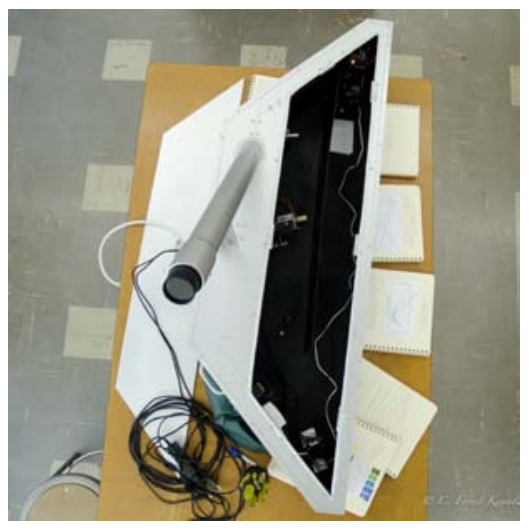

Figure 1. Montana State University “Dark Star” Spectrograph

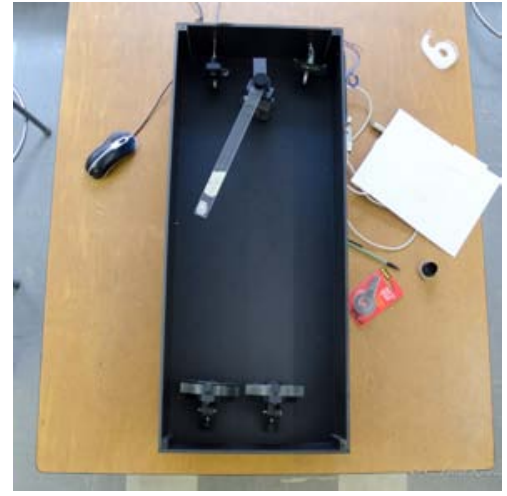

Figure 2. Harding University Spectrograph 


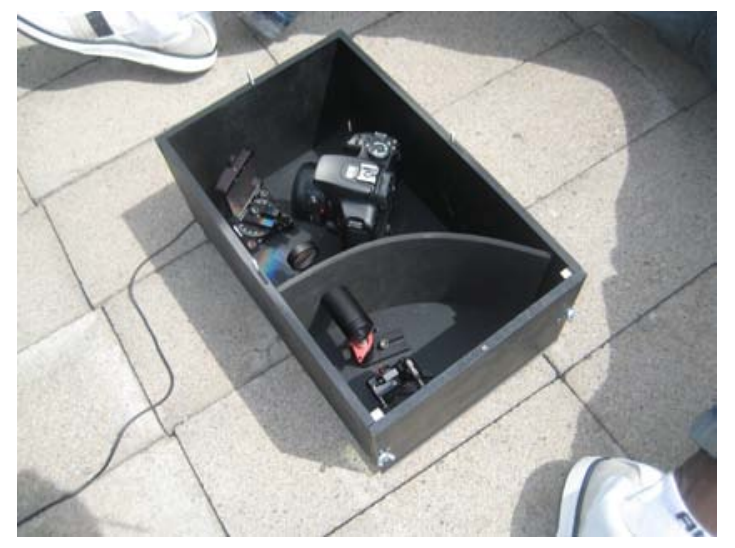

Figure 3. Montgomery College Spectrograph

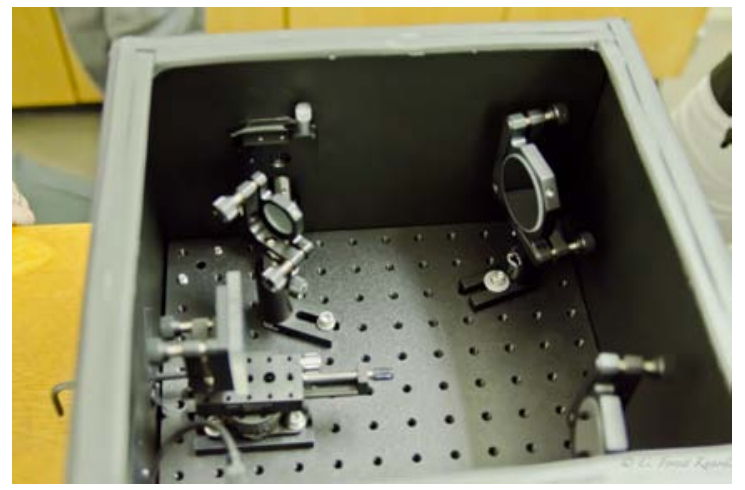

Figure 4. San Diego State University Spectrograph

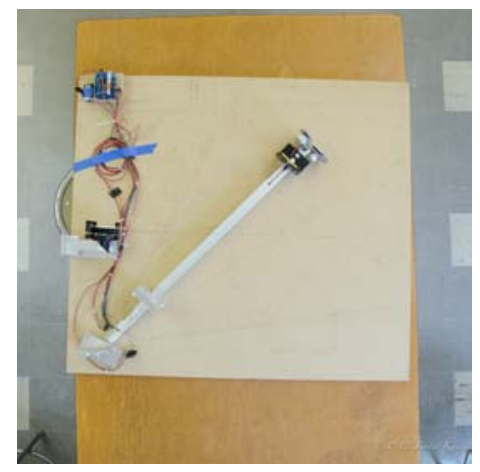

Figure 5. Flathead Valley Community College Spectrograph

Proc. of SPIE Vol. $848184810 Z-8$

Downloaded From: https://www.spiedigitallibrary.org/conference-proceedings-of-spie on 26 Apr 2023 Terms of Use: https://www.spiedigitallibrary.org/terms-of-use 


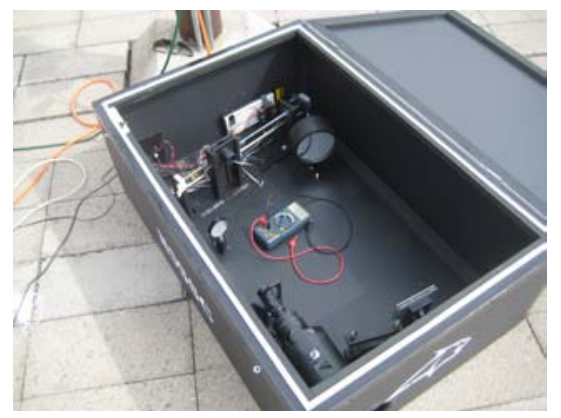

Figure 6. Montana State University “Greek” Spectrograph

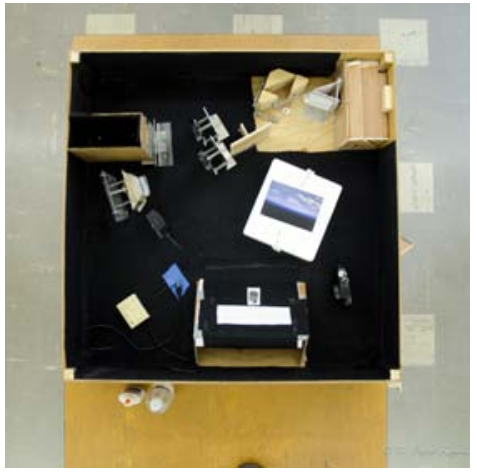

Figure 7. Montana State University “Rowland’s Dark Scintillations” Spectrograph

Proc. of SPIE Vol. $848184810 Z-9$

Downloaded From: https://www.spiedigitallibrary.org/conference-proceedings-of-spie on 26 Apr 2023 Terms of Use: https://www.spiedigitallibrary.org/terms-of-use 


\section{Categories and Winners of the 2011-2012 Competition}

\subsection{Best Science Observation Award}

Montgomery College in Rockville, Md. Team members: Michael Satinu, Yosheph Feseha, John Silk, and Lampouguin Yenkoidiok-Douti. Team advisers: Carrie Fitzgerald and Ryan Fitzgerald.

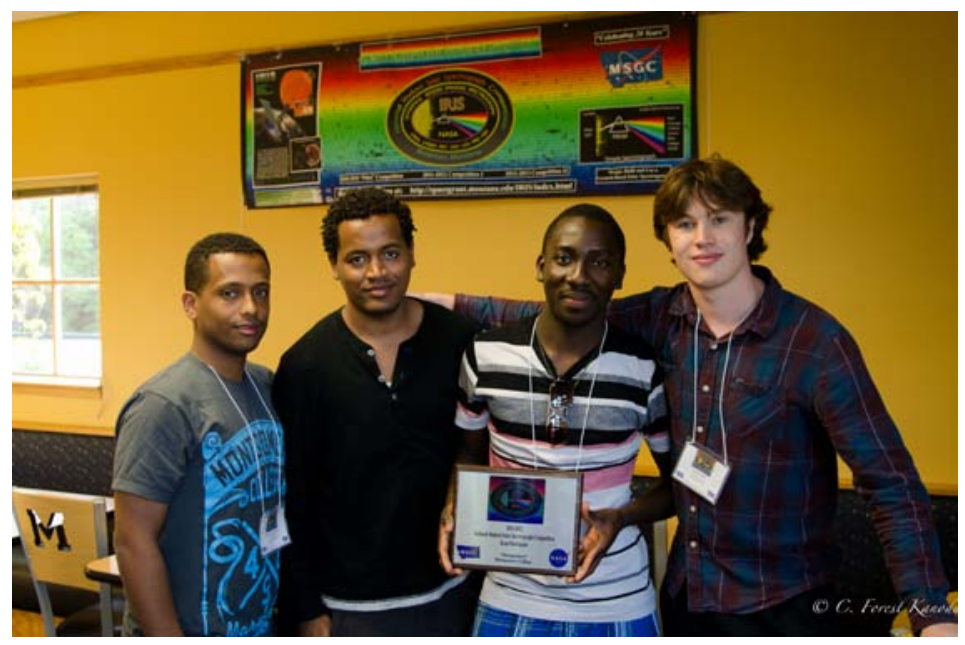

Figure 8. NSSSC Team Montgomery Community College

\subsection{Best Presentation of Results Award}

San Diego State University. Team members: Heath Kirkwood, Scott Patterson, Michael Baude, Emily Mitchell, and Kenny Sokolowski. Team adviser: Matt Anderson.

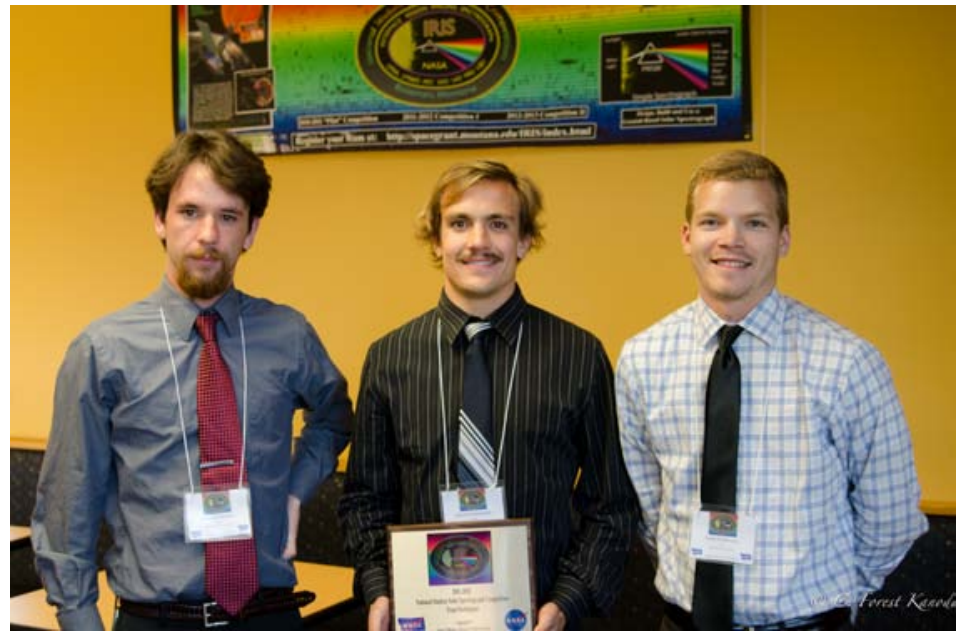

Figure 9. NSSSC Team San Diego State University 


\subsection{Best Spectrograph Design Award}

Montana State University "Darkstar” team. Team members: Ethan Keeler, Courtney Peck, Drew Moen and Chris Zimny. Team adviser: Kevin Repasky.

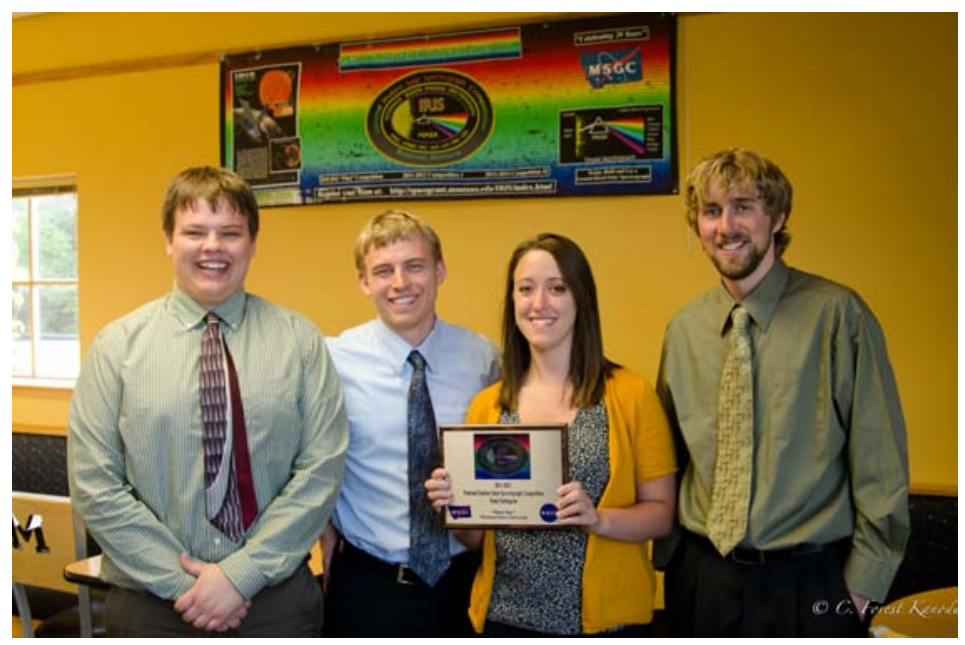

Figure 10. NSSSC Team Montana State University “Darkstar”

\subsection{Best Spectrograph Build Award}

Montana State University "The Greek" team. Team members: Jamesen Motley, Ginny Price, Dave Riesland and Jeff Ibey. Team adviser: Nathan Pust.

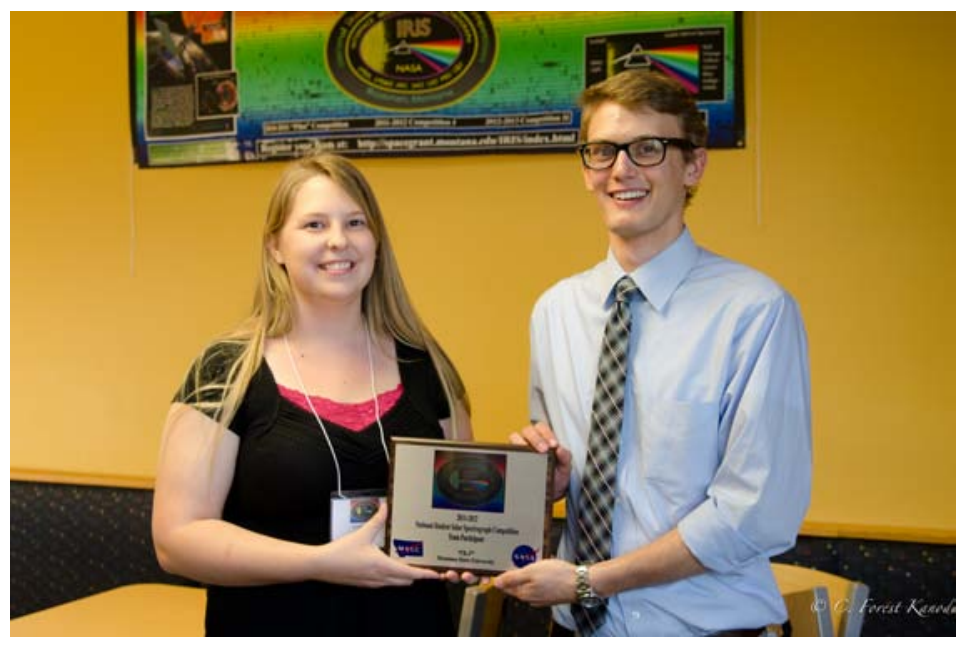

Figure 11. NSSSC Team Montana State University “Greeks” 


\subsection{Honorable Mention Category - The Highest Demonstrated Resolution with Largest Bandwidth Award}

Harding Solar Spectroscopy Group from Harding University. Team members: Grant Arthur, Taylor Gammon, and Brandon Huber. Team advisor: Ed Wilson

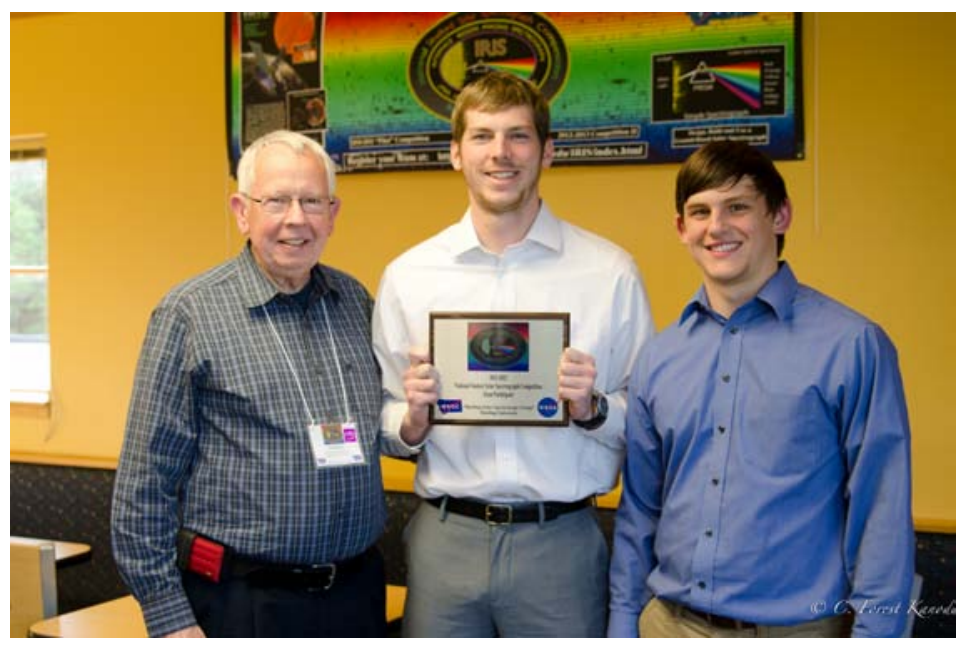

Figure 12. NSSSC Team Harding University

\subsection{Honorable Mention Category - The Most Fun Science Award}

Flathead Valley Community College Spectrogeeks. Team members: Alex Korchmar, Gunnar Pope and Jerry Johnson. Team advisor: Jim Boger.

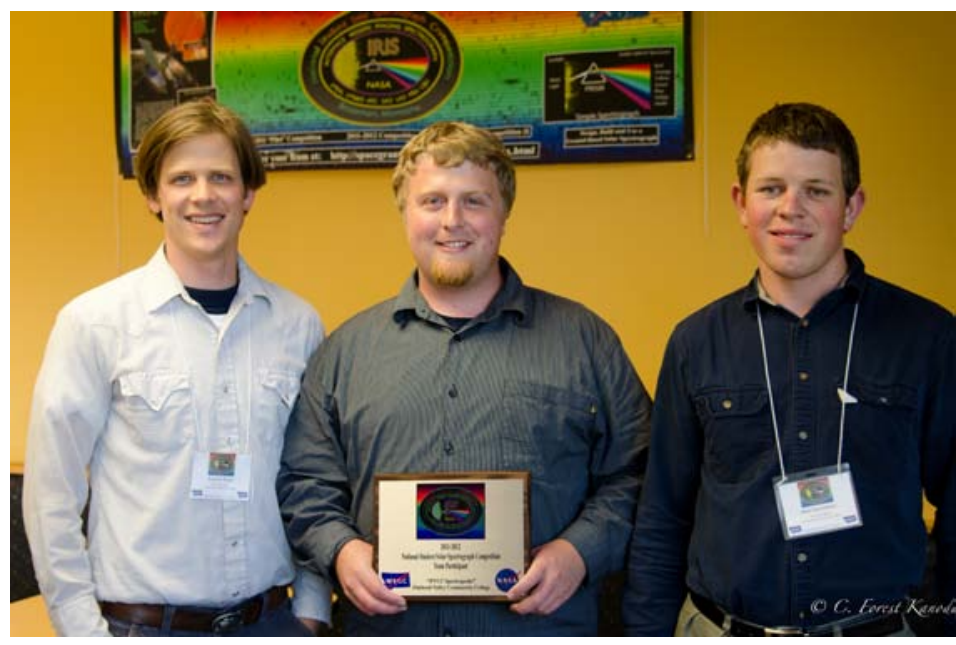

Figure 13. NSSSC Team Flathead Valley Community College 
Montana State University "Rowland's Dark Scintillations" team. Team members: Brenden Lawrence, Brett Green, John Hoover and Mike Hansen. Team advisor: Mitch Hobish.

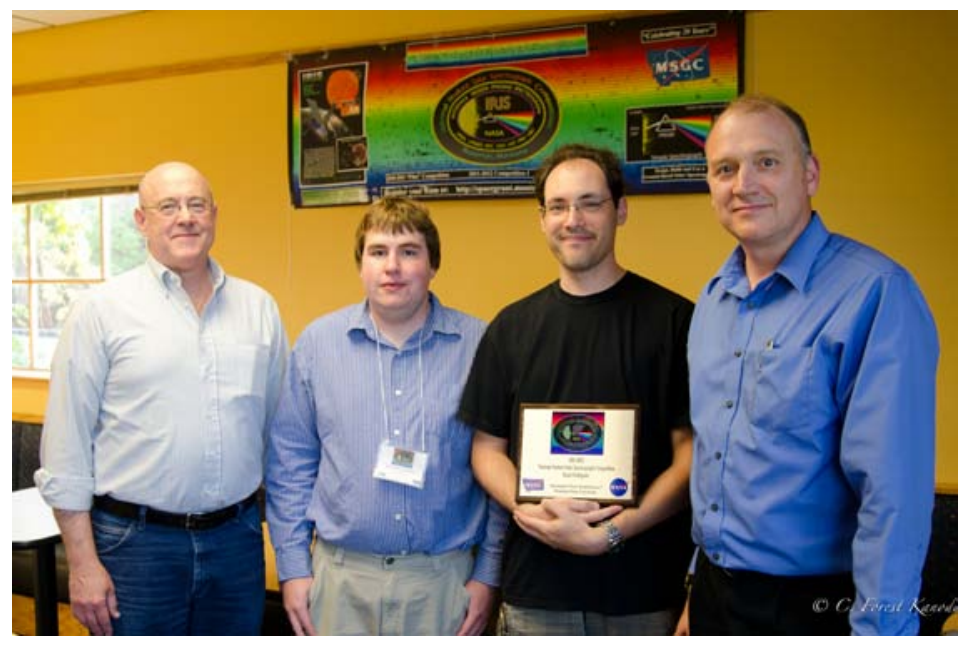

Figure 14. NSSSC Team Montana State University "Rowlands”

\subsection{Participant Award}

Montana Tech “Ad Astra Per Ardua” team. Team members: Charles Shaw and Justin Palin. Team advisor: Laurie Battle.

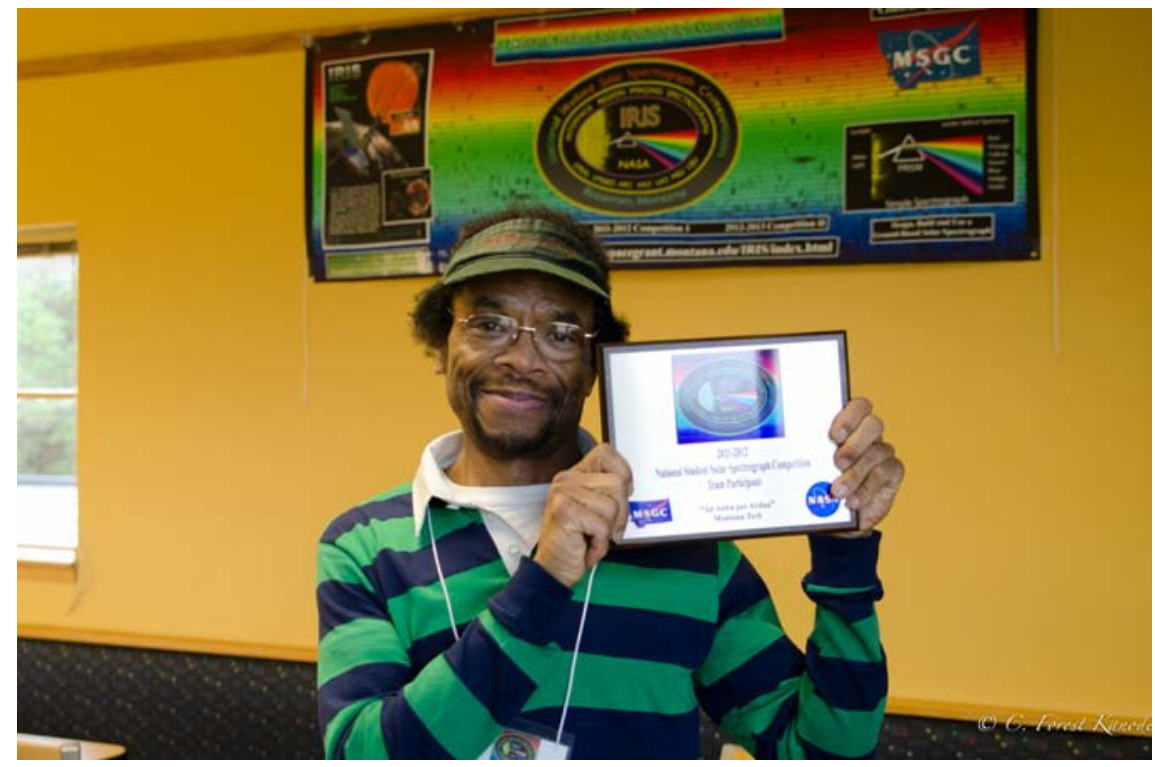

Figure 15. NSSSC Team Montana Tech 


\section{Conclusions}

"The concept of having undergraduates design, build and test a scientific instrument is certainly unique as far as I know. This is a marvelous opportunity for young people to develop high level skills in instrument building. Using the instrument to answer science questions makes it even better. I commend and thank you for this wonderful experience. All of us will learn so much as we successfully complete this project. NSSSC provides participating students a better chance for admission to the graduate school of their choice. Also, they will receive better fellowships when they are accepted to graduate school. It will give some of them a direction for their career. I know of no other opportunity to engage in instrument design and application." - Edmond Wilson, Faculty Advisor Harding University

"The opportunity to work on a real project has been a true motivation for our students who can feel isolated at a small school with no significant research going on.” - Jim Boger, Faculty Advisor Flat Head Valley Community College

\section{Opportunity for 2012-2013 Competition}

Ask yourself the following questions: Are you looking for a real world design problem? Do you want to participate on an interdisciplinary team? Do you want to travel to the 'Big Sky' state? Do you want experience with mechanical components, optics, electronics and software? Do you want a chance to win scholarship and travel prizes? If you answered yes to these questions then this competition is for you! Get your team together and register today.

College students interested in designing a spectrograph can now register for next year's competition. Build awards of $\$ 2,000$ per team are available for teams that register by Sept. 30. Registration and more information is available at http://www.spacegrant.montana.edu/iris/

Social Media Link: http://www.facebook.com/NASANS3 


\section{Acknowledgement}

An amazing group of people came together to design, support, judge, and participate in the NSSSC.

Thank you to everyone for making the 2011-2012 NSSSC a successful and rewarding event!

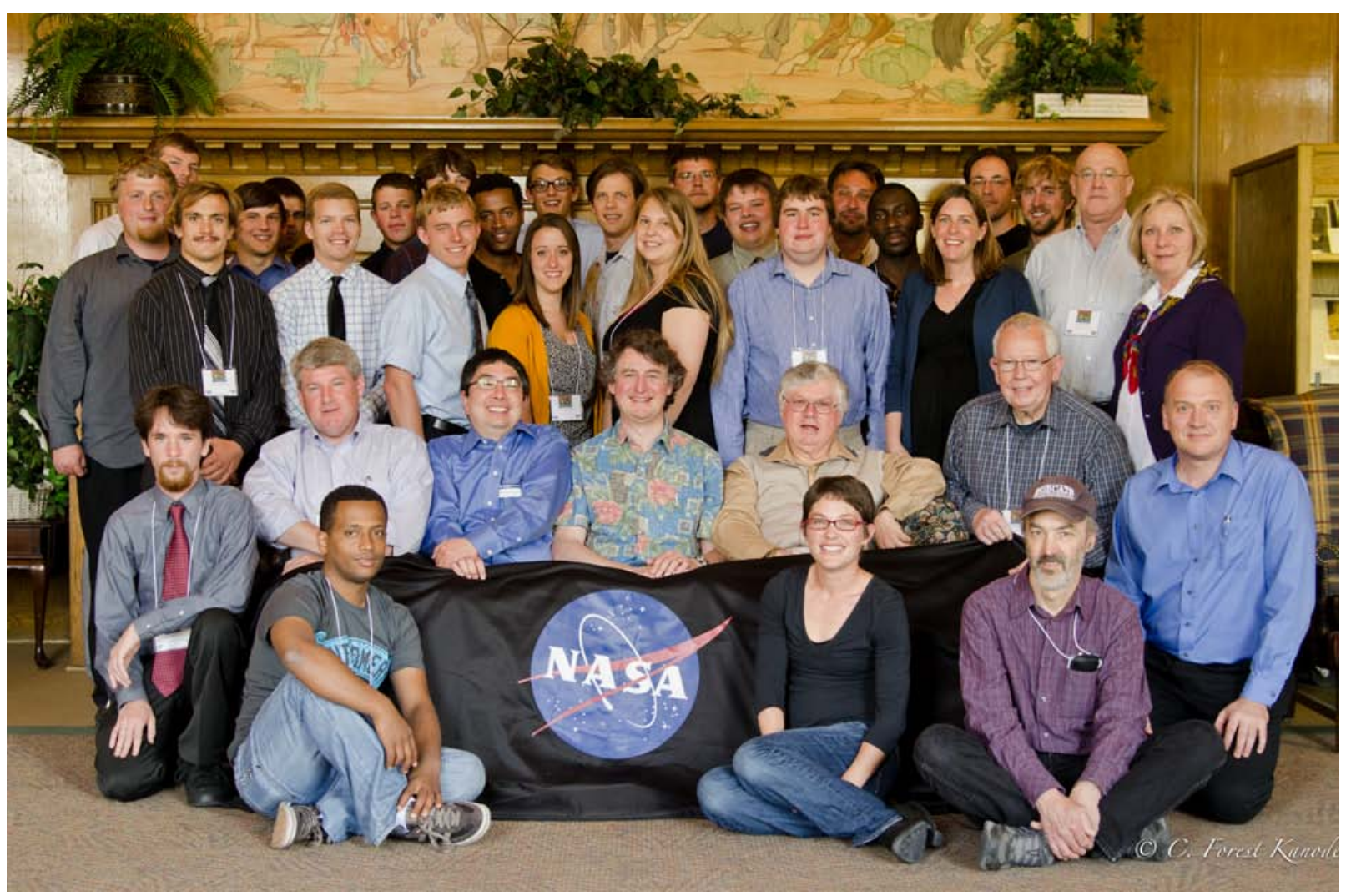

Figure 16. NSSSC Team 